\title{
Pearls \& Oy-sters: Idiopathic Normal Pressure Hydrocephalus With Synucleinopathy
}

\section{Diagnosis and Treatment}

Sang-Won Han, MD, Young Ho Park, MD, PhD, Nayoung Ryoo, MD, Kitae Kim, MD, Jung-Min Pyun, MD, and SangYun Kim, MD, PhD

Neurology ${ }^{\circledR}$ 2021;97:196-199. doi:10.1212/WNL.0000000000012099
Correspondence Dr. Park kumimesy@snubh.org

\section{Pearls}

- Idiopathic normal pressure hydrocephalus (iNPH) is characterized by the classic triad of gait disturbance, urinary incontinence, and cognitive impairment in the presence of ventriculomegaly without known risk factors for communicating hydrocephalus.

- Shunt surgery is indicated for patients with iNPH who respond to the removal of CSF.

\section{Oy-sters}

- Striatal dopaminergic deficit on dopamine transporter (DAT) scan can be seen in patients with iNPH.

- Abnormal DAT imaging may be seen in patients with an unfavorable long-term outcome of shunt surgery.

- For patients with iNPH with clinical features suggesting synucleinopathy such as REM sleep behavior disorder, DAT scan could be considered to identify concurrent synucleinopathy before shunt surgery, even in cases with initial response to high-volume lumbar puncture.

A 70-year-old man presented with a 2-year history of progressive disturbances of gait, balance, control of urination, and cognition. He also had mild constipation, but he did not have other symptoms suggesting dysautonomia, such as orthostatic dizziness, syncope, or sweating abnormalities. He had no history of head trauma, meningitis, or intracranial hemorrhage. Neurologic examination revealed postural instability, bradykinesia, and subtle limb rigidity. His gait was slow with reduced arm swing and stride length (mean stride length $20.1 \mathrm{~cm}$, walking speed $20.3 \mathrm{~cm} / \mathrm{s}$ ) (video 1 ). Motor and sensory functions were normal. Deep tendon reflexes were normal, and there was no ataxia or pathologic reflexes. He scored 22 on the Mini-Mental State Examination (MMSE). Routine laboratory tests were normal. Brain MRI showed enlarged lateral ventricles (Evans index 0.32) and disproportionately enlarged subarachnoid space hydrocephalus (DESH) (figure). ${ }^{1} \mathrm{He}$ was diagnosed with iNPH and underwent daily lumbar puncture (LP) with removal of $50 \mathrm{~mL}$ of CSF for 2 consecutive days. Routine CSF analysis was unremarkable. After LP, mean stride length and walking speed increased to $76.6 \mathrm{~cm}$ and $72.4 \mathrm{~cm} / \mathrm{s}$, respectively (video 2). Ventriculoperitoneal shunt (VPS) surgery was recommended but refused by the patient and his family. Interestingly, the improvement of gait was sustained for several months. The mean stride length and walking speed were $76.0 \mathrm{~cm}$ and $71.3 \mathrm{~cm} / \mathrm{s}$, respectively, after 7 months of LP (video 3).

The patient was lost to follow-up. Two years after the initial visit, he again presented with aggravated gait. He was taking levodopa/carbidopa $(100 / 25 \mathrm{mg}) 3$ times a day that was prescribed elsewhere. His family also reported that he exhibited dream enactment behavior. $\mathrm{He}$ had no history of visual hallucination or fluctuation of cognition. The mean stride length and
MORE ONLINE

Videos

From the Department of Neurology, Seoul National University College of Medicine and Seoul National University Bundang Hospital, Republic of Korea.

Go to Neurology.org/N for full disclosures. Funding information and disclosures deemed relevant by the authors, if any, are provided at the end of the article. 


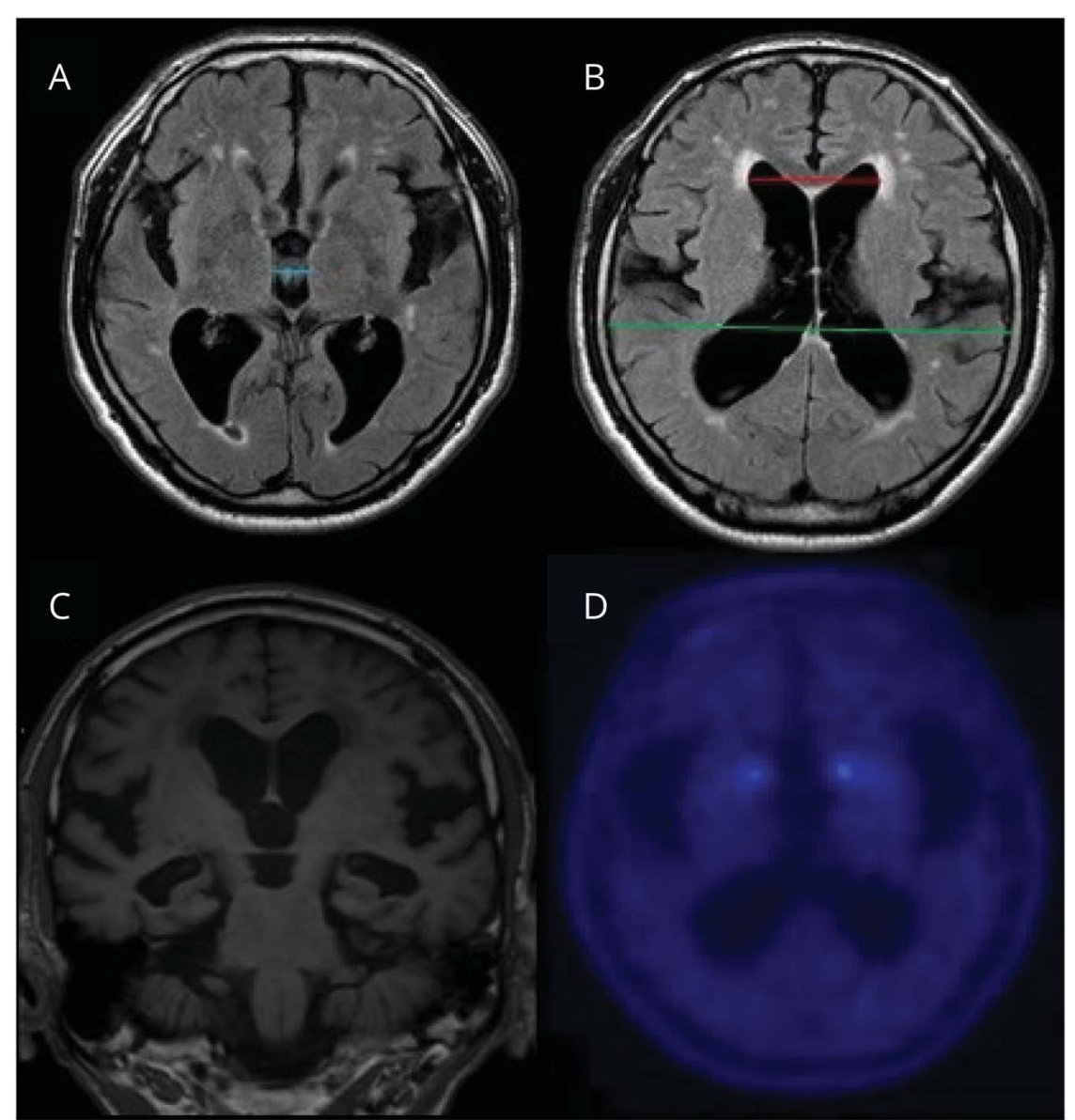

\section{E}

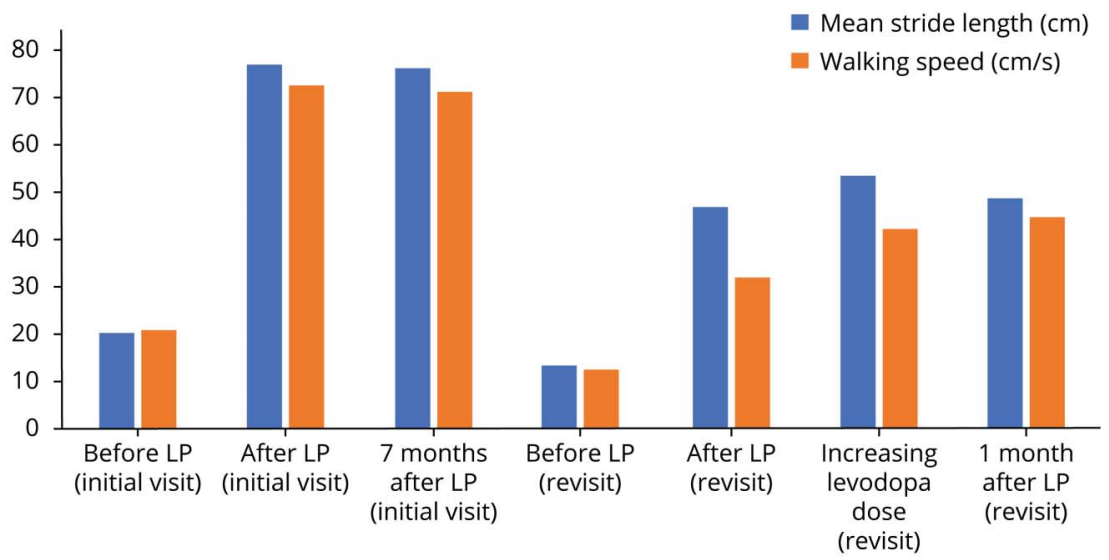

(A) Axial fluid-attenuated inversion recovery (FLAIR) image at the initial visit shows a widened third ventricle with a span of $1.2 \mathrm{~cm}$ (blue line). (B) Axial FLAIR image at the initial visit shows measurement of Evans index: the diameter of the frontal horns (red line) was $4.4 \mathrm{~cm}$, the widest brain diameter (green line) was $13.6 \mathrm{~cm}$, and the Evans index was 0.32. (C) Coronal T1-weighted image at 2 years after the initial visit shows widened sylvian fissures and enlarged temporal horn of lateral ventricle. (D) Axial FP-CIT PET image shows reduced dopamine transporter uptake bilaterally throughout the striatum, including the caudate nucleus and the putamen. (E) Bar graph shows the change in mean stride length and walking speed during the clinical course. LP = lumbar puncture. walking speed were $13.0 \mathrm{~cm}$ and $12.1 \mathrm{~cm} / \mathrm{s}$, respectively (video 4). He scored 24 on the MMSE. MRI findings of enlarged lateral ventricles and DESH were similar to the previous MRI (figure). After he underwent LP with removal of $50 \mathrm{~mL}$ of CSF, the mean stride length and walking speed increased to $46.6 \mathrm{~cm}$ and $31.7 \mathrm{~cm} / \mathrm{s}$, respectively (video 5). ${ }^{18} \mathrm{~F}-\mathrm{N}$-3-fluoropropyl-2 $\beta$ carboxymethoxy-3 $\beta$-(4-iodophenyl)-nortropane (FP-CIT) PET showed reduced DAT uptake bilaterally throughout the striatum, including the caudate nucleus and the putamen (figure).
The dose of levodopa/carbidopa was increased to $250 / 50 \mathrm{mg}$ 3 times a day. The mean stride length and walking speed slightly increased to $53.4 \mathrm{~cm}$ and $41.6 \mathrm{~cm} / \mathrm{s}$, respectively (video 6). Gait was still improved 1 month after LP (mean stride length $48.5 \mathrm{~cm}$, walking speed $44.6 \mathrm{~cm} / \mathrm{s}$ ) (video 7). Although gait improved after high-volume LP, the parkinsonian features on neurologic examination, dream enactment behavior, and reduced striatal DAT uptake on FP-CIT PET support an underlying synucleinopathy in this patient. 


\section{Discussion}

Normal pressure hydrocephalus is characterized by the classic triad of gait disturbance, urinary incontinence, and cognitive impairment in the presence of ventriculomegaly, which is ameliorated by the removal of CSF. ${ }^{2}$ The diagnosis of iNPH is made by excluding known risk factors for communicating hydrocephalus including meningitis, traumatic brain injury, subarachnoid hemorrhage, and brain irradiation. ${ }^{2}$ Shunt surgery is indicated for patients with iNPH who respond to the removal of CSF. ${ }^{2}$ It has been shown that patients with iNPH present with normal presynaptic DAT binding in the striatum. ${ }^{3}$ However, although our patient's gait disturbance was improved by LP with CSF removal, FPCIT PET showed reduced DAT binding throughout the striatum, including the caudate nucleus and the putamen. Given that $25 \%$ of patients with iNPH who underwent shunt surgery were revealed to have a diagnosis other than $\mathrm{iNPH}^{4}$ our patient might have a concomitant neurodegenerative disorder affecting presynaptic nigrostriatal neurons. His dream enactment behavior suggests underlying synucleinopathy such as Parkinson disease or dementia with Lewy bodies. ${ }^{5}$ In addition, the degree of improvement in gait after the second LP was not as robust as that resulting from the first LP, which could be a sign of concurrent neurodegeneration in our patient.

It has been recently reported that striatal dopaminergic deficit on DAT scan was common (46.7\%) in patients with $\mathrm{iNPH}^{6}$; furthermore, 1 year after VPS, 6 (42.9\%) of 14 patients with reduced striatal DAT binding had a favorable outcome, whereas $13(81.3 \%)$ of 16 patients with normal striatal DAT binding had a favorable outcome. Similarly, it has been shown that reduced striatal DAT binding was common $(46.2 \%)$ in patients with $\mathrm{iNPH}$, and 3 (60.0\%) of 5 patients with reduced striatal DAT binding had a favorable postshunt outcome, whereas $6(85.7 \%)$ of 7 patients with normal striatal DAT binding had a favorable postshunt outcome. ${ }^{7}$ DAT imaging studies also indicated that the caudate nucleus was affected more than the putamen in patients with iNPH. ${ }^{7,8}$ A recent study indicated that 8 patients with $\mathrm{iNPH}$ who had additional neurologic diseases had persistent improvement, whereas 10 (43.5\%) of 23 patients without concomitant neurologic diseases had persistent improvement. ${ }^{4}$ In addition, a patient with iNPH comorbid with progressive parkinsonism was found to have concomitant synucleinopathy with REM sleep behavior disorder (RBD) and decreased DAT binding in the striatum 3 years after shunt surgery. ${ }^{9}$ Considering these results, the long-term outcome of shunt surgery might not be favorable in patients with iNPH with concomitant synucleinopathy. Therefore, it could be recommended for patients with iNPH with clinical features suggesting synucleinopathy such as RBD to undergo DAT imaging before shunt surgery and discuss the long-term outcome of the surgery with neurologists and neurosurgeons.

It has been shown that the improvement of gait after the removal of CSF rarely persists for more than a few days in patients with iNPH. ${ }^{2}$ However, the response after CSF removal sometimes could be sustained, as in our patient, for a few months. ${ }^{10}$ Although the exact mechanism is not clear, the prolonged response might be attributed to the elasticity of the ventricular wall. ${ }^{10}$ After LP, the total resistance and subsequently the tensile strength of the ventricular wall are decreased. ${ }^{\mathrm{e} 1}$ If the tensile strength of the ventricular wall is decreased further after LP, the effect of LP could be profound and prolonged. ${ }^{\mathrm{e} 2}$ Repeated removal of CSF every 7 months was reported to prevent decline in gait performance in patients with iNPH ineligible for shunt surgery. ${ }^{\mathrm{e} 3}$

Larger studies are needed to investigate the prevalence of concomitant synucleinopathy and to determine safe and effective treatment options.

\section{Acknowledgment}

This work was supported by the National Research too loose Foundation of Korea (grant 2020R1C1C1013718).

\section{Study Funding}

The authors report no targeted funding.

\section{Disclosure}

The authors report no disclosures relevant to the manuscript. Go to Neurology.org/ $\mathrm{N}$ for full disclosures.

\begin{tabular}{|c|c|c|}
\hline Name & Location & Contribution \\
\hline $\begin{array}{l}\text { Sang-Won } \\
\text { Han, MD }\end{array}$ & $\begin{array}{l}\text { Seoul National University } \\
\text { College of Medicine and Seoul } \\
\text { National University Bundang } \\
\text { Hospital }\end{array}$ & $\begin{array}{l}\text { Design and } \\
\text { conceptualization of the } \\
\text { study, analysis and } \\
\text { interpretation of the data, } \\
\text { drafting and revising of the } \\
\text { manuscript }\end{array}$ \\
\hline $\begin{array}{l}\text { Young Ho } \\
\text { Park, MD, } \\
\text { PhD }\end{array}$ & $\begin{array}{l}\text { Seoul National University } \\
\text { College of Medicine and Seoul } \\
\text { National University Bundang } \\
\text { Hospital }\end{array}$ & $\begin{array}{l}\text { Design and } \\
\text { conceptualization of the } \\
\text { study, critical revision of } \\
\text { manuscript for important } \\
\text { intellectual content, study } \\
\text { supervision }\end{array}$ \\
\hline $\begin{array}{l}\text { Nayoung } \\
\text { Ryoo, MD }\end{array}$ & $\begin{array}{l}\text { Seoul National University } \\
\text { College of Medicine and Seoul } \\
\text { National University Bundang } \\
\text { Hospital }\end{array}$ & $\begin{array}{l}\text { Acquisition of data and } \\
\text { analysis and interpretation }\end{array}$ \\
\hline $\begin{array}{l}\text { Kitae Kim, } \\
\text { MD }\end{array}$ & $\begin{array}{l}\text { Seoul National University } \\
\text { College of Medicine and Seoul } \\
\text { National University Bundang } \\
\text { Hospital }\end{array}$ & Acquisition of data \\
\hline $\begin{array}{l}\text { Jung-Min } \\
\text { Pyun, MD }\end{array}$ & $\begin{array}{l}\text { Seoul National University } \\
\text { College of Medicine and Seoul } \\
\text { National University Bundang } \\
\text { Hospital }\end{array}$ & Analysis and interpretation \\
\hline $\begin{array}{l}\text { SangYun } \\
\text { Kim, MD, } \\
\text { PhD }\end{array}$ & $\begin{array}{l}\text { Seoul National University } \\
\text { College of Medicine and Seoul } \\
\text { National University Bundang } \\
\text { Hospital }\end{array}$ & $\begin{array}{l}\text { Design and } \\
\text { conceptualization of the } \\
\text { study, critical revision of the } \\
\text { manuscript for important } \\
\text { intellectual content }\end{array}$ \\
\hline
\end{tabular}




\section{References}

1. Ambarki K, Israelsson H, Wåhlin A, Birgander R, Eklund A, Malm J. Brain ventricular size in healthy elderly: comparison between Evans index and volume measurement. Neurosurgery. 2010;67:94-99.

2. Williams MA, Relkin NR. Diagnosis and management of idiopathic normal-pressure hydrocephalus. Neurol Clin Pract. 2013;3:375-385.

3. Tatsch K, Poepperl G. Nigrostriatal dopamine terminal imaging with dopamine transporter SPECT: an update. J Nucl Med. 2013;54:1331-1338.

4. Espay AJ, Da Prat GA, Dwivedi AK, et al. Deconstructing normal pressure hydrocephalus: ventriculomegaly as early sign of neurodegeneration. Ann Neurol. 2017;82: 503-513.

5. Postuma R, Gagnon J, Vendette M, Fantini M, Massicotte-Marquez J, Montplaisir J. Quantifying the risk of neurodegenerative disease in idiopathic REM sleep behavior disorder. Neurology. 2009;72:1296-1300.
6. Broggi M, Redaelli V, Tringali G, et al. Normal pressure hydrocephalus and parkin sonism: preliminary data on neurosurgical and neurological treatment. World Neurosurg. 2016:90:348-356.

7. Allali G, Garibotto V, Mainta IC, Nicastro N, Assal F. Dopaminergic imaging separates normal pressure hydrocephalus from its mimics. J Neurol. 2018;265:2434-2441.

8. Lee JY, Park SB, Lee M, Ju H, Im K, Kwon KI. Detailed visual assessment of striata dopaminergic depletion in patients with idiopathic normal pressure hydrocephalus: unremarkable or not? BMC Neurol. 2020;20:277.

9. Shimada H, Shimada Y. Progressive parkinsonism three years after shunt surgery in a patient with idiopathic normal pressure hydrocephalus. Intern Med. 2020;59: 2183-2186.

10. Lim T, Yong S, Moon S. Repetitive lumbar punctures as treatment for normal pressure hydrocephalus. Eur Neurol. 2009:62:293-297.

Data available from Dryad (additional references): doi:10.5061/dryad.66t1g1k11

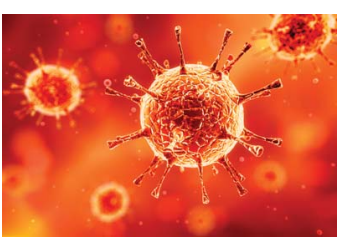

\section{COVID-19 and Neurologic Disease: Call for Papers!}

The editors of Neurology are interested in papers that address the neurological aspects of COVID-19 infection and challenges to the management of patients with chronic neurological conditions who have, or are at risk for, the infection. Relevant papers that pass initial internal review will undergo expedited peer review and online publication. We will consider papers posted in preprint servers.

Submit observational studies and clinical trials as Articles and case series and case reports under the Clinical/Scientific Notes category to https://submit.neurology.org/ today!

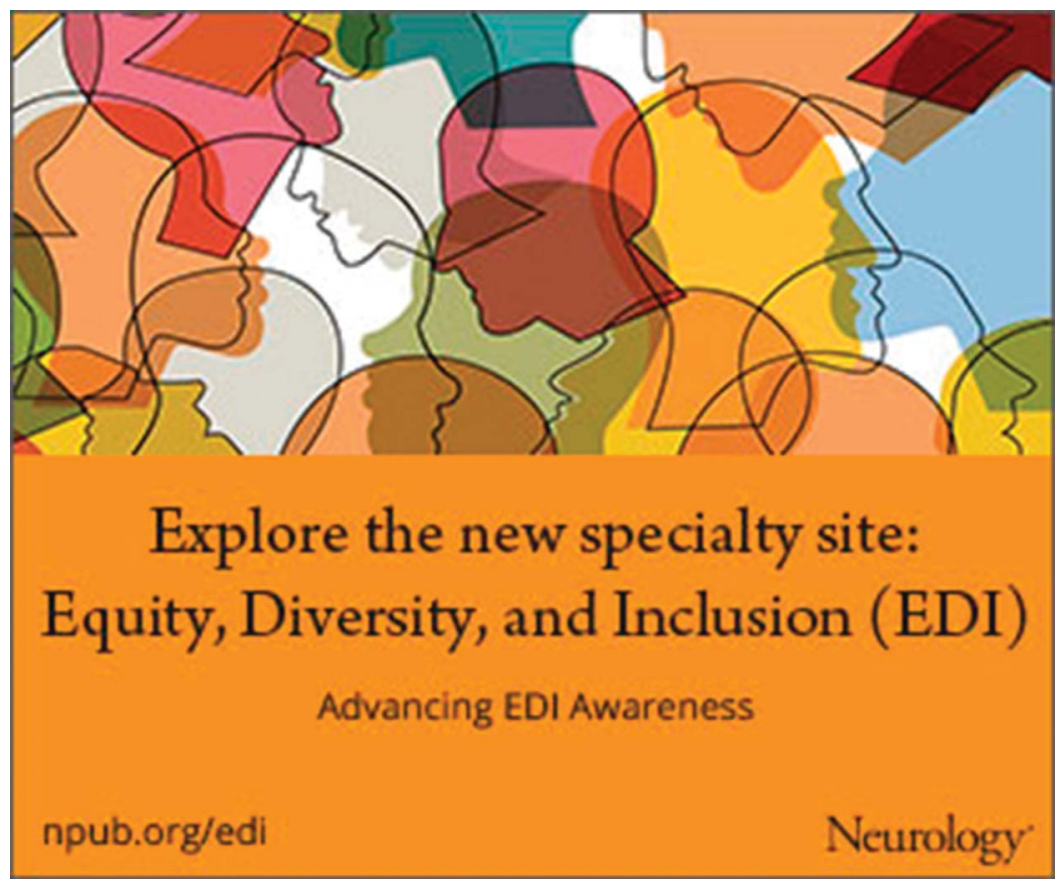




\section{Neurology}

\section{Pearls \& Oy-sters: Idiopathic Normal Pressure Hydrocephalus With Synucleinopathy:}

Diagnosis and Treatment

Sang-Won Han, Young Ho Park, Nayoung Ryoo, et al. Neurology 2021;97;196-199 Published Online before print April 30, 2021

DOI 10.1212/WNL.0000000000012099

This information is current as of April 30, 2021

\section{Updated Information \&} Services

References

Subspecialty Collections

Permissions \& Licensing

Reprints including high resolution figures, can be found at: http://n.neurology.org/content/97/4/196.full

This article cites 10 articles, 3 of which you can access for free at: http://n.neurology.org/content/97/4/196.full\#ref-list-1

This article, along with others on similar topics, appears in the following collection(s):

All Cognitive Disorders/Dementia

http://n.neurology.org/cgi/collection/all_cognitive_disorders_dementia Cerebrospinal Fluid

http://n.neurology.org/cgi/collection/cerebrospinal_fluid

Hydrocephalus

http://n.neurology.org/cgi/collection/hydrocephalus

\section{PET}

http://n.neurology.org/cgi/collection/pet

Information about reproducing this article in parts (figures,tables) or in its entirety can be found online at:

http://www.neurology.org/about/about_the_journal\#permissions

Information about ordering reprints can be found online:

http://n.neurology.org/subscribers/advertise

Neurology ${ }^{\circledR}$ is the official journal of the American Academy of Neurology. Published continuously since 1951, it is now a weekly with 48 issues per year. Copyright () 2021 American Academy of Neurology. All rights reserved. Print ISSN: 0028-3878. Online ISSN: 1526-632X.

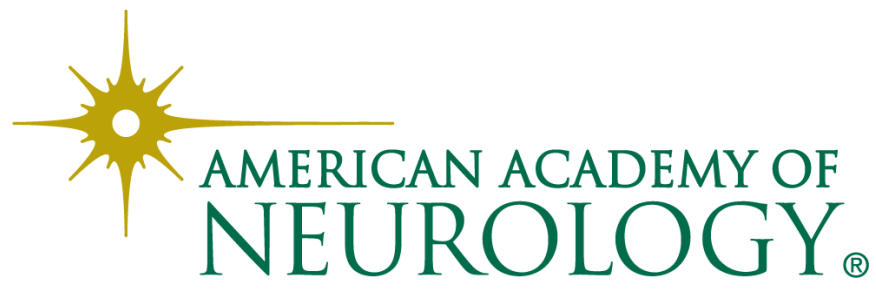

